\title{
Knowledge and practice of health managers in using information technology in health system
}

\author{
Suvada Švrakić ${ }^{\star 1,2}$, Amer Ovčina $^{1,2}$ \\ ${ }^{1}$ Clinic for vascular diseases, Clinical Center of University of Sarajevo, Bolnička 25, 71000 Sarajevo, Bosnia and Herzegovina \\ ${ }^{2}$ Faculty of Health Studies, University of Sarajevo, Bolnička 25, 71000 Sarajevo, Bosnia and Herzegovina
}

\begin{abstract}
Introduction: Information systems today are an inevitable link in the health care system. Health care institutions and health workers in modern society, depend on information systems in everyday tasks of organizing institutions. The goals of the study were to determine the existence and application of information technology in the health care system and of the Clinical Center of Sarajevo University and, Primary Health Care Center of Sarajevo Canton, as well as to assess knowledge and practice of managers in nursing of the Organizational units of the University Clinical Center in Sarajevo and Primary Health Care Center of Sarajevo Canton. Method: The study is of a prospective type. It will use a questionnaire based on which we will be able to determine the knowledge and application in practice of managers in nursing of knowledge about information technology in the health care system. The study was conducted from June $1^{\text {st }}-$ August $1^{\text {st }} 2010$.

Results: It is expected that most health institutions in the Canton Sarajevo has no organized information network system. Most managers' nurses use e-mail in order to quickly contact other colleagues and exchange experiences. A large number of nurse's managers in health institutions use computer technology in their daily work in order to make medical reports.

Conclusions: Health system and information technology are in close relationship, although still insufficiently applied in everyday work. Management of organizational units in health care in the future will not be able to successfully function without the use of information technology in their daily work.
\end{abstract}

(C) 2011 All rights reserved

Keywords: health managers, information technology, health system.

\section{Introduction}

Information technology (IT) by the American Association for Information Technology is defined as "the study, design, development, implementation and support or management of computer information systems (IS) trough software applications and hardware". IT is using computers and computer programs to convert, store, protect, process, and to securely send and receive information. The term "Information technology" often includes a much broader array of technology areas. All those activities deal with IT professionals, from installing application programs to designing com-

\footnotetext{
* Corresponding author: Suvada Švrakić, Clinical Center of University of Sarajevo, Bolnička 25, 71000 Sarajevo, Bosnia and Herzegovin Phone: +387 332970 00; Fax: +387 33441815 E-mail: imarinov@inet.ba
}

Submitted 10. October 2011 / Accepted 24. November 2011 plex computer networks and information systems. Some of these activities include: networking and computer hardware engineering, design of software and databases, as well as management and administration of information systems (1). Information technology is a general term that describes a technology that helps the production, manipulation, storage, communication and information distribution. First to use the term "Information Technology" was Jim Domsik from Michigan in November 1981. The term is used in order to modernize until then used term "data processing". At that time Domsik worked as a computer manager in the auto industry (2). Today, information technology increases the speed, power, and become very sophisticated, and can link together a wide range of devices in the network that surrounds the globe. They provide new ways of learning, work, enter- 
tainment, and new ways of conducting business. Some have suggested that these changes are revolutionary and that they change the world, while others argue that changes are evolutionary. It is reasonable to study the phenomenon that created a new world and new economy through technological innovation, increase in economic performance and connectivity of the world on a global level (3). Medical informatics is a prerequisite for the development of modern medicine and health systems with a significant role in collecting, processing and publication of data. The patient is an active participant in the proceedings of treatment, and for this are partly responsible also the IT technologies with which we encounter every day. Medical facilities are available on the internet today which is for the medicine of immeasurable educational significance, because ease of online search of published data makes them available to all users (4). It should be noted that the possibilities of information technology to develop are much faster than the legal regulation why this area the legal acts have yet to cover, and therefore does not rely on data protection only on legal and technical protection, but it is also extremely important to respect the moral and ethical principles (4). Information systems can play an important role in knowledge management, helping organizations to create and store them, while managing information system helps managers to better plan, effectively organize, direct and control the functioning of the organization, in short, to effectively and efficiently manage its storing, dissemination and application of knowledge, and embrace basis of this knowledge. One of the basic functions of information systems (IS) is that managers, supplying relevant information, obtain insight into the behavior of organizations so that they can more effective and efficient use their skills of planning, organizing, directing and controlling in order to achieve desirable development, growth and prosperity of the organization. From the information systems is expected to assist the effective and efficient functioning of the health organization by providing the right information at the right time, in the proper form and in the right quantity to the right person - user or the organization (5). The goals of this study were to determine the existence and application of information technology in the health system of Clinical Center University of Sarajevo and Public Health Care Institutions of Canton Sarajevo, as well as to assess knowledge and practice on the use of information technology managers in the nursing organizational unit of the Clinical Center of Sarajevo University and Primary Health Care Institutions of Canton Sarajevo.

\section{Methods}

\section{Study design}

The study was of prospective type and it was conducted in two separate medical institutions Primary Health Care Institutions of Canton Sarajevo and the Clinical Center of Sarajevo University (CCUS), among the chief nurses - managers of organizational units. The survey covered 17 chief nurses of the organizational units in CCUS and 8 chief nurses of the Primary Health Care Centers of the Sarajevo Canton.

\section{Procedure}

We used a questionnaire composed of questions related to knowledge, attitudes and practices of information technology use in the health system. The questionnaire was anonymous, so that respondents could feel free to answer questions honestly. The study was carried out from June $1^{\text {st }} 2010$ to July $1^{\text {st }} 2010$. The research results were processed in the Microsoft Access database and presented as graphics and tables.

\section{Results}

The results of our study are listed in Figures 1-11, and Tables 1-3.

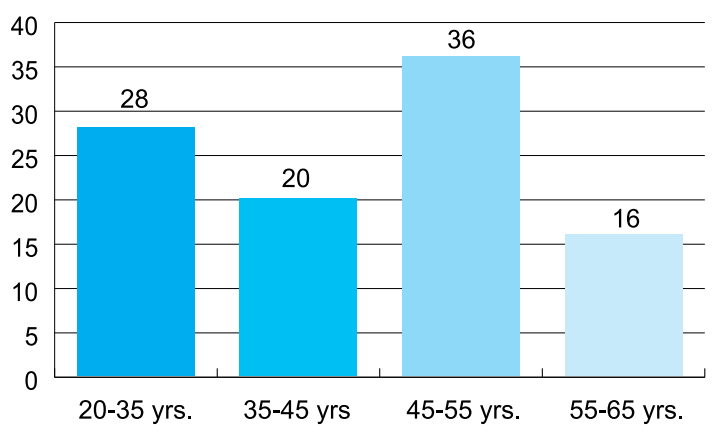

FIGURE 1. Distribution of respondents according to age structure 


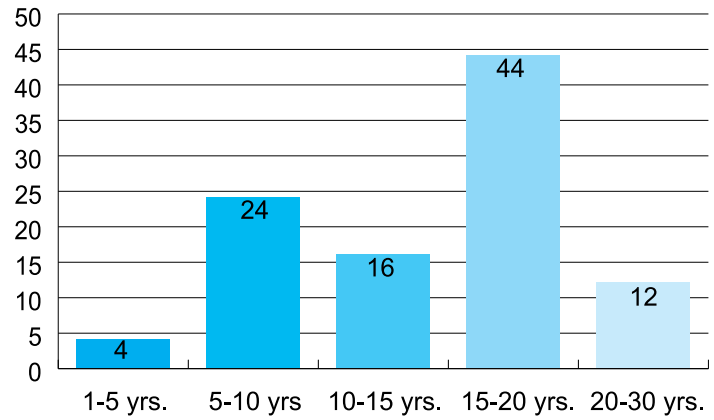

FIGURE 2. Years of service of respondents

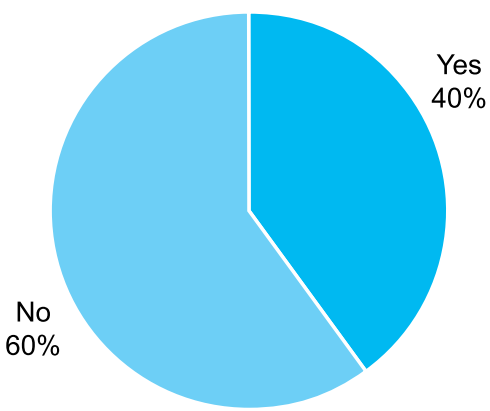

FIGURE 4. The existence of a network system at the workplace

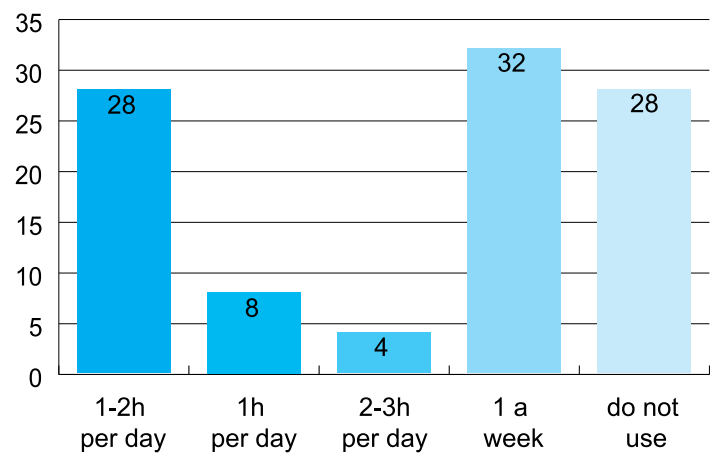

FIGURE 6. Frequency of Internet use in daily work

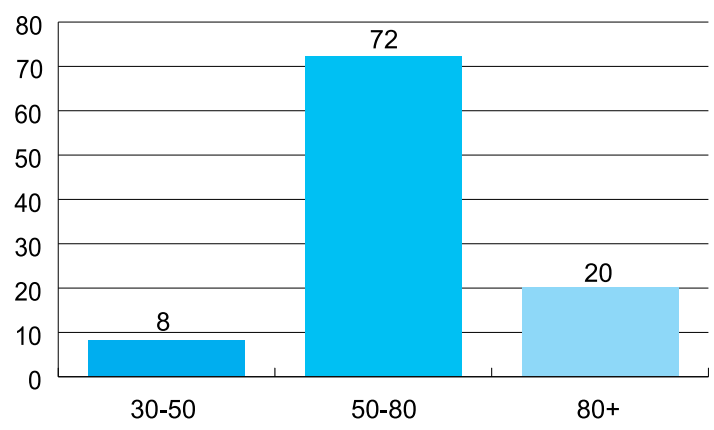

FIGURE 8. Number of employees at the organizational unit

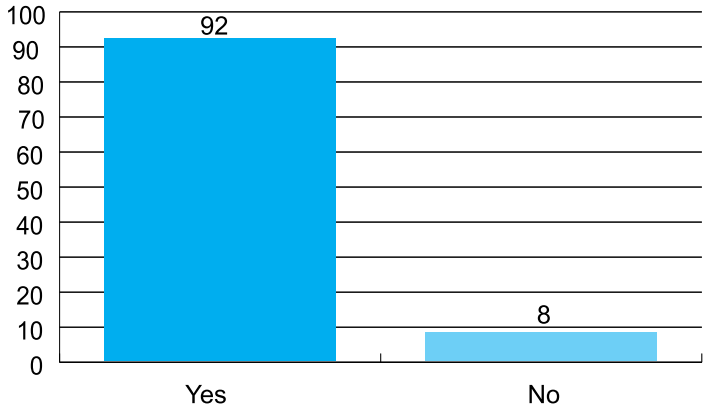

FIGURE 3. Having a computer in the workplace

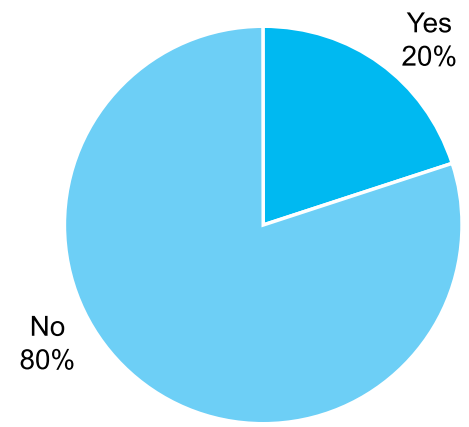

FIGURE 5. Links with other organizational units within the health network

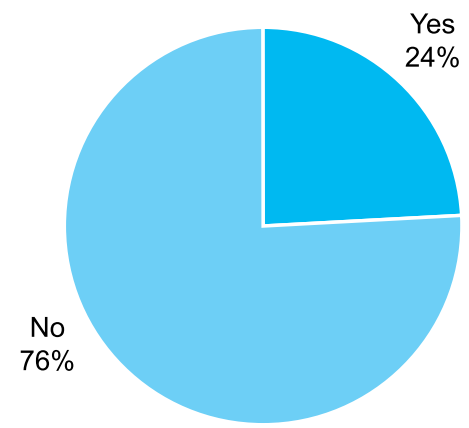

FIGURE 7. Help from the use of the Internet in their daily work (reports, decisions, etc.)

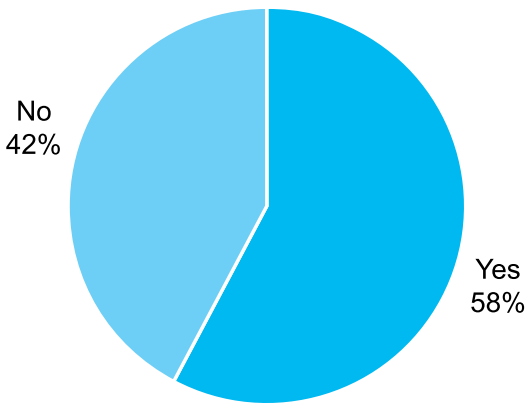

FIGURE 9. Education of employees to use information technology 


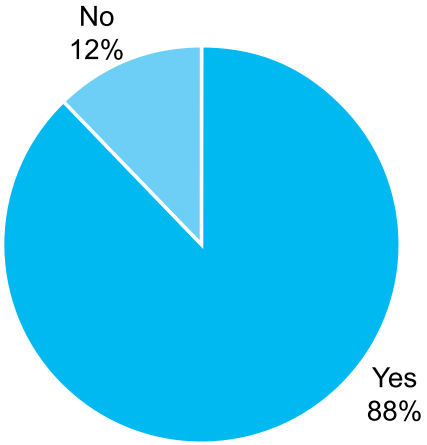

FIGURE 10. Satisfaction with knowledge and use of information technology in managerial work

TABLE 1. Self evaluation of knowledge about the Internet

\begin{tabular}{ccc}
\hline Evaluation & $\mathrm{N}$ & $\%$ \\
\hline 1 & 15 & 60 \\
2 & 0 & 0 \\
3 & 6 & 24 \\
4 & 4 & 16 \\
5 & 0 & 0 \\
\hline
\end{tabular}

TABLE 3. Evaluation of health care assistants work on computer and with information technologies

\begin{tabular}{ccc}
\hline Evaluation & $\mathrm{N}$ & $\%$ \\
\hline 1 & 0 & 0 \\
2 & 6 & 24 \\
3 & 9 & 36 \\
4 & 8 & 32 \\
5 & 2 & 8 \\
\hline
\end{tabular}

\section{Discussion}

The survey was conducted among 17 chief nurses managers of organizational units of the CCUS and 8 chief nurses managers of Primary Health Care Centers in Sarajevo Canton. In our study there were no male respondents, given that the nursing profession is largely female profession. The largest number of respondents belonged to age group 45-55 years 9 (36\%), while a smaller number belonged to the age group 20-35 years 7 (28\%) subjects. Regarded the years of service it can bee seen that these are the respondents with the service of 15-20 years or $11(44 \%)$ of them. Total of 23 (92\%) respondents cited the fact that they have workplace with computer equipment. Network system within

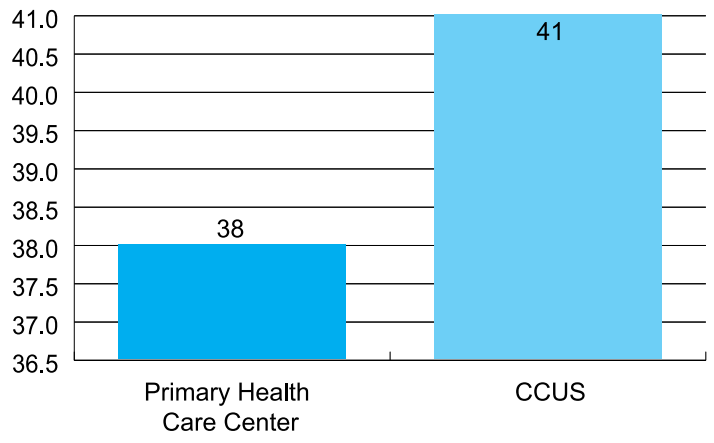

FIGURE 11. Correlation of using IT in their daily work of nurses, managers at the Primary Health Care Center and Clinical Center University of Sarajevo

TABLE 2. Evaluation of the use of information technology in decision-making in everyday work

\begin{tabular}{ccc}
\hline Evaluation & $\mathrm{N}$ & $\%$ \\
\hline 1 & 2 & 8 \\
2 & 6 & 24 \\
3 & 0 & 0 \\
4 & 12 & 48 \\
5 & 5 & 20 \\
\hline
\end{tabular}

the organizational unit has 10 (40\%) subjects, while from total of $10(40 \%)$ only $2(20 \%)$ respondents stated that the system is connected to network with other organizational units. It is surprising that $15(60 \%)$ respondents assessed their knowledge of internet with grade 1, while $4(16 \%)$ respondents rated their knowledge of the Internet with grade 4. The same number of respondents stated that the Internet during the day is using $7^{1 / 2} / 2 \mathrm{~h}$ and $7(28 \%)$ respondents that they does not use it at all, the majority of respondents reported that the Internet is used once during the week or $32 \%$. Worrying is the fact that only $6(24 \%)$ respondents reported that the internet helps them make decisions for daily work, preparation of reports and other guidelines for the work. Number of employees in the institution (OU) is between 50-80, which stated 18 (72\%) subjects. Most respondents were trained to work on a computer - 13 (52\%). When asked to assess the computer skills of their staff, the responses were divided, and approximately equal in the evaluation from 1-5. Most of the chief nurses - managers said that they are satisfied with the level of knowledge of computer skills and 
knowledge of information technology - 22 (88\%). Comparing the results of using IT in their daily work we can notice that there is greater use by the chief nurses in CCUS in relation to the Primary Health Care Institution of Canton Sarajevo or in $41 \%$ of cases.

\section{Conclusions}

Research has shown that knowledge of information technology and its application is unsatisfactory for nurses and managers of major organizational units in health care. Age structure, as well as respondents years of service are not motivating factor for additional training for the more sophisticated use of information technology. The existing physical resources (computer equipment, Internet access) are not adequately used in health care organizations. Preoccupation with everyday tasks of chief nurses - managers at the organizational units does not provide enough space for active use of information technology. By use of information technology (network system, internet) nurses - managers can fully facilitate the conduct of daily work - contracting, report writing, faster and more efficient exchange of experiences which contribute to improving health services.

\section{Competing interests}

Authors declare that there are no competing interests related to this study.

\section{References}

1. Flower J. Transformations of 21st century health care, Part 1 . Beyond the digital divide. Health Forum J 2003;46:8-13

2. Gell G. Side effects and responsibility of medical informatics. Int J Med Inform 2001;64:69-81.

3. Information Technology in Health
Care - a General Outline of Ethical Issues. European Network for Biomedical Ethics. Dostupno na URL adresi 2007.: http://www.izew.unituebingen.de/bme/volume42.html

4. Majdančič Ž. Medicina, informatika, etika. U: Kern J. Hercigonja-Szekeres M. Medicinska informatika
5. Kudumović M. Zdravstvena informatika i informacioni sistemi za zdravstveni menadžment. Skripta za postdiplomski studij menadžment u zdravstvu. Fakultet zdravstvenih studija, Univerzitet u Sarajevu. 